\title{
PENGARUH LOGISTIK SERVIC E QUALITY TERHADAP KEPUASAN KONSUMEN PADA PRODUK CV CAHAYA MULIA DI KOTA BIMA
}

\begin{tabular}{|c|c|}
\hline & $\begin{array}{l}\text { ABSTRAK } \\
\text { Penelitian ini bertujuan mencari pengaruh logistik service quality } \\
\text { terhadap kepuasan konsumen pada produk CV Cahaya Mulia di } \\
\text { Kota Bima, menggunakan motode survey dengan menyebarkan } \\
\text { kuesioner kepada konsumen yang pernah membeli produk dari CV }\end{array}$ \\
\hline Imran $^{1}$; Sri Ernawati ${ }^{2}$ & $\begin{array}{l}\text { Cahaya Mulia Kota Bima. Jumlah sampel } 100 \text { orang dengan teknik } \\
\text { purposive sampling dalam menentukan respondenhya. }\end{array}$ \\
\hline $\begin{array}{l}\text { 12Sekolah Tinggi Ilmu } \\
\text { Ekonomi (Stie) Bima } \\
\text { Email: } \\
\text { sriernawati.stiebima@gma }\end{array}$ & $\begin{array}{l}\text { Penggumpualan data dengan menggunakan observasi, kuesioner } \\
\text { dan studi pustaka. Analisis data menggunakan regresi linear } \\
\text { sederhana dengan SPSS 20.00. Hasil yang diperoleh dalam } \\
\text { penelitian ini yaitu logistik service quality berpengaruh terhadap } \\
\text { kepuasan konsumen pada produk CV Cahaya Mulia di Kota Bima }\end{array}$ \\
\hline
\end{tabular}

Kata Kunci: Logistik Service Quality, Kepuasan Konsumen.

\section{A. PENDAHULUAN}

Persaingann yang terjadi sekarang ini akan membuat pelaku bisnis harus memikirkan strategi yang mampu menarik hati pelanggan sehingga bisa menguasai pasar. Untuk menguasai pasar pebisnis harus menerapkan strategi yang kuat dan akurat agar bisa memenangkan pasar. Pelanggan menjadi faktor penentu dipasar sehinggan mengetahui keinginan dan kebutuhan mereka menjadi hal yang harus dipertimbangkan.

Dalam perjalanan waktu, pedoman dalam melaksanakan kegiatan bisnis menjadi semakin berubah kearah yang lebih maju. Di era globalisasi konsep mengenai pelanggan sangat penting, dimana konsep ini menekankan pada pebisnis yang harus mementingkan keinginan konsumen karena konsumen kunci keberhasilan perusahaan( Winarno \& Absor, 2018). Kegiatan fisik menjadi mengambil peranyang sangat penting, diantaranya membuat barang yang disediakan di pasar tersedia dengan lancer dan cepat dinikmati oleh konsumen, (Kolter,2016).

Logistics service quality merupakan penyempurnaan dari kualitas pelayanan yang bisa digunakan untuk menilai kepuasan konsumen bidang logistik. saat logistics service quality bekerja sampai akurat, maka konsumen akan puas. Konsumen yang puas akan membuat perusahaan terus maju dan berkembang. perusahaan dapat menjaga konsumen yang setia dan akan terus menggunakan jasa perusahaan sehinggan penggunaan jasa akan semakin meningkat, Japarianto(2018)

Logistics dan Service Quality dikemukakan sebagai usaha diaman dikerjakan untuk menghadapi tuntutan hasrat dan kemauan konsumen akan produk dengan memaksimalkan distribusi yang baik, agar produk bisa sampai ke konsumen dengan lancar dan tepat sesuai dengan keinginan konsumen sehingga konsumen akan merasa puas .(Japarianto, 2018). Kualitas layanan logistik sudah dikenal karena peran yang penting untuk kepuasan pelanggan, Rafiq \& Jaafar (2007). sehingga bagi penyedia distribusi lebih akurat untuk meningkatkan kualitas 
distribusi logistik dan berusaha untuk menjadi lebih proaktif dalam memberikan layanan yang lebih baik dalam rangka mendapatkan kepuasan pelanggan, Thai (2013). Menurut Mentzer (2016) dimensi dimensi logistics service quality bukan untuk menilai kegiatan fisik tetapi juga hal-hal lain yang lebih kualitatif. Indikator Variabel logistic service quality menurut Ho et al (2012) Time liness, accuary of order, quality of information dan quality of contac personel

Kepuasan konsumen merupakan ekpetasi yang dialami konsumen setelah melihat hasil yang diperoleh dengan pengorbanan yang dilakukan, (Malhotra, $\mathrm{N}$ ,2015). lebih luas mengenai kepuasan konsumen dimana rasa yang dialami konsumen dengan membandingkan kesan yang didapat dengan harapan konsumen , Kotler (2009). Indikator Variabel Kepuasan Konsumen. Handi irawan (2004) Konfirmasi Harapan, Pembelian Ulang, Ketidakpuasan Konsumen

Penelitian tentang logistics service quality sudah perna diteliti orang beberapa ahli sebelumnya, logistics service quality cocok diterapkan pada perusahaan yang bergerak dibidang jasa seperti expedisi, delivery, pelayanan jasa, kontraktor dan lain-lain, misalkan oleh Japarianto (2018) dimana usaha yang dikerjakan perusahaan untuk menghadapi keinginan dan kebutuhan konsumen terhadap subuah produk dengan mengoptimalkan distribusi dengan tepat dan akurat sampai ketangan konsumen sehinggan kepuasan konsumen bisa tercipta. Sudah terbukti bahwa kualitas layanan logistik memiliki pengaruh dengan kinerja dan itu menjadi keunggulan kompetitif bagi perusahaan (Politis, et al, 2014). Kualitas layanan memiliki dampak positif pada kepuasan pelanggan, dan juga berdampak positif terhadap loyalitas pelanggan secara langsung atau tidak (melalui kepuasan pelanggan) (Otsetova, 2017). Banyak penelitian yang menganalisis dampak dari kualitas layanan yang baik adalah kepuasan dan loyalitas, dan ini menciptakan konsep yang berbeda (Saura, et al, 2008).

CV Cahaya mulia telah menghasilkan produk diantaranya, Lemari Etalase Alumannium , Lemari Pakaian Alumanium , Rak Piring Alumanium, pintu dan jendela berbahan Alumanium Kaca, Rolling door, Pagar Besi, Terali Jendela, Knopi, dan Produk Produk Lainya yang berbahan alumanium, Kaca dan Besi dengan kualitas memuaskan, sekarang berbicara memuaskan tidak bisa dijadikan ukuran untuk dapat memenangkan pasar. Berdasarkan hasil observasi peneliti dilihat bahwa masalah yang ada di CV Cahaya mulia yaitu kekurangan alat kerja, sepeti mesin pemotong, bor otomatis dan pengukuran lainnya, sehingga perkerjaan yang ada di CV Cahaya mulia sedikit terhambat yang mengakibatkan waktu pengantaran produk ke konsumen menjadi terlambat dari waktu yang sudah disepakati..

Berdasarkan dari latar belakang diatas dan hasil penelitian dari beberapa penelitian menyatakan pentingnya sebuah perusahaan menerapakan Logistics dan Service Quality agar tercipta kepuasan konsumen, jika konsumen merasa puas makan loyalitas akan terjadi. Maka peneliti tertarik melakukan penelitian dengan judul "Pengaruh logistik service quality terhadap kepuasan konsumen pada produk CV Cahaya Mulia di Kota Bima" 


\section{B. METODE PENELITIAN}

Pendekatan kualitatif dengan metode survey digunakan dalam penelitian ini dengan. Survey merupakan moetode mengumpulkan data dengan memberikan kuesioner kepeda responden, dimana kuesioner berupa pernyataan. ( Harsono, 2010) mengenai produk CV Cahaya Mulia di Kota Bima.

Penentuan populasi disesuaikan dengan kebutuhan penelitian yaitu konsumen pada produk CV Cahaya Mulia di Kota Bima. Pengambilan sampel dengan teknik purposive sampling dimana penentuan sampel berdasarkan kriteria tertentu yang diseuaikan dengan kebutuhan penelitian. Hartono, (2010). sampel dalam penelitian ini berjumlah 100 orang

Regresi sederhana digunakan untuk menganalisis data dalam penelitian ini. Analisis regresi di pakai untuk mengetahui pengaruh variabel bebas dengan variabel terikat, Ghozali (2006).

Rumus regresi linear sederhana sebagi berikut:

$\mathrm{Y}^{\prime}=\mathrm{a}+\mathrm{bX}$

Keterangan:

$\mathrm{Y}^{\prime}=$ Kepuasan konsumen

$\mathrm{X}=$ logistik service quality

a $=$ Konstanta

$\mathrm{b}=$ Koefisien regresi

Untuk menguji pengaruh antar variabel menggunakan SPSS (Statistical Service Product Solutions) versi 20.00. SPSS dibuat oleh Norman Nie mahasiswa lulusan fakultas ilmu politik dari Stanford University tahun 1968. SPSS digunakan untuk memberikan penjelasan terhadap permasalahan di beberapa ilmu seperti social, analisis keadaan pasar, kesehatan, politik dan lain-lain. Pengujian Hipotesis menggunakan Uji Parsial (Uji t). Menurut (Ghozali, 2006) uji t dikerjakan untuk menguji antar variabel secara terpisah dengan standar signifikan $5 \%$.

\section{HASIL PENELITIAN DAN PEMBAHASAN}

Penelitian ini mengkaji tentang bagaimana pengaruh logistik service quality terhadap kepuasan konsumen pada produk CV Cahaya Mulia di Kota Bima. Peneliti membagikan 100 kuesioner kepada konsumen CV Cahaya Mulia Kota Bima, Allhamdulillah semua kuesioner dikembalikan.

1. Profil responden berdasarkan jenis kelamin

Tabel 1

Hasil deskripsi responden

\begin{tabular}{lll}
\hline Jenis kelamin & Jumlah & persen \\
\hline Laki laki & 75 & 70.0 \\
\hline perempuan & 25 & 30,0 \\
\hline total & 100 & 100,0 \\
\hline
\end{tabular}

Sumber : Data diolah 2020

Berdasarkan data di atas dapat di lihat responden berjenis kelamin laki laki yaitu $(70 \%)$, Sedangkan jumlah responden berjenis kelamin perempuan (30\%) 
2. Profil responden berdasarkan usia

Tabel 2

Hasil deskripsi responden

\begin{tabular}{lll}
\hline Usia & Jumlah & persen \\
\hline 17 thn -30 thn & 70 & 70,0 \\
\hline 31 thn -40 thn & 30 & 30,0 \\
\hline & 100 & 100,0 \\
\hline
\end{tabular}

Sumber : Data diolah 2020

Berdasarkan pada data di atas dapat di lihat usia 17 tahun - 30 tahun sebanyak (70\%) sedangkan usia 31 tahun - 40 tahun sebanyak (30\%).

3. Karakteristik responden berdasarkan tingkat pendidikan

Tabel 3

Hasil deskripsi responden berdasarkan tingkat pendidikan

\begin{tabular}{lll}
\hline Pendidikan & Jumlah & persen \\
\hline Wiraswasta & 54 & 54,0 \\
\hline ASN (Aparatur Sipil Negara) & 46 & 46,0 \\
\hline & 46 & 100,0 \\
\hline
\end{tabular}

Sumber : Data diolah 2020

Berdasarkan pada data di atas dapat di lihat bahwa pendidikan yaitu wirawasta 54 responden (54\%) dan ASN (Aparatur Sipil Negara) 46 responden $(46 \%)$.

\section{Hasil Regresi Linear sederhana}

Uji regresi linear sederhan digunakan untuk menganalisis pengaruh antar variabel yang diteliti. Pengajuan dilakukan dengan mengunakan program SPSS 20.00 windows

Tabel 4

Hasil Analisis Regresi Linear sederhana

Coefficients $^{\mathrm{a}}$

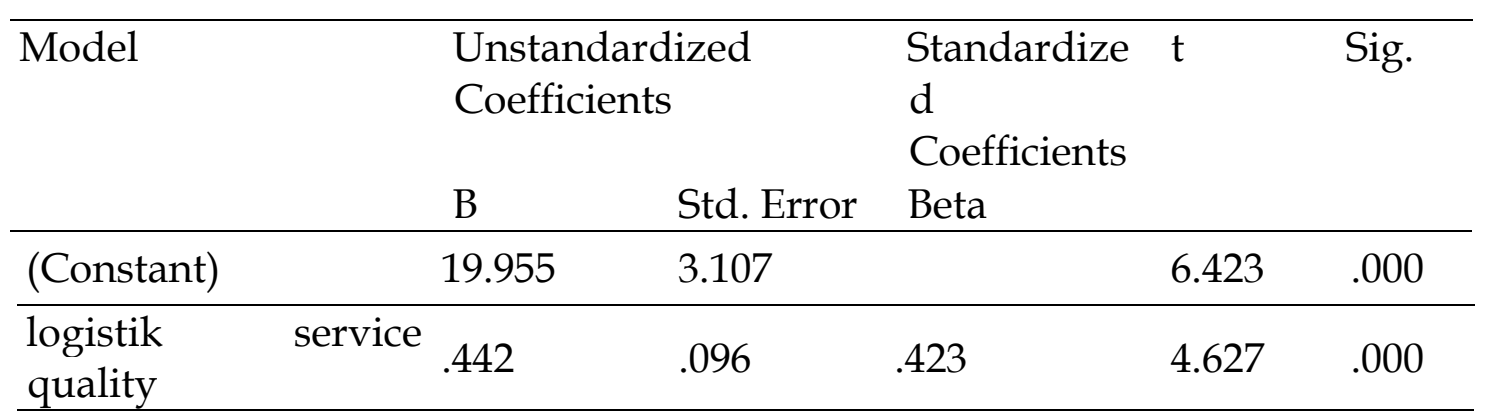

a. Dependent Variable: Kepuasan Konsumen

Sumber : Data diolah 2020

Dari data diatas dibuat persamaan sebagai berikut . $Y=19.955+0,442 X$. Berdasarkan bersamaan tersebut, Maka dapat di jelaskan sebagai berikut: 
a. Data konstanta sebesar 19.955 di simpulkan bahwa variabel logistik service quality dianggap konstanta. Maka kepuasan konsumen akan sebesar 19.955.

b. Data koefisien beta variabel logistik service quality bernilai 0,442 dapat disimpulkan terjadi perubahan variabel logistik service quality $(X)$ senilai satu satuan terjadi perubahan Kepuasan konsumen (Y) sebesar 190,442 satuan

\section{Hasil Uji Koefisien Korelasi dan Determinasi}

Tabel 5

Hasil Uji Determinasi

Model Summary

\begin{tabular}{|c|c|c|c|c|}
\hline Model & $\mathrm{R}$ & R Square & $\begin{array}{l}\text { Adjusted } \\
\text { Square }\end{array}$ & $\begin{array}{l}\text { R Std. Error of the } \\
\text { Estimate }\end{array}$ \\
\hline
\end{tabular}

\begin{tabular}{|c|c|c|c|c|}
\hline 1 & $.423^{a}$ & 179 & 17 & 346080 \\
\hline
\end{tabular}

Data diaras menunjukan nilai Adjusted $\mathrm{R}^{2}$ sebesar 0.423 , dapat dinyakan bahwa Kepuasan Konsumen dipengaruhi oleh logistik service quality sebesar 42,3\% dan sisa sebesarnya 57,7\% dipengaruhi oleh faktor lain.

\section{Uji Hipotesis}

Tabel 6

Hasil Uji Hipotesis

Coefficients ${ }^{a}$

\begin{tabular}{llllll}
\hline Model Unstandardized Coefficients & $\begin{array}{l}\text { Standardize } \\
\mathrm{d}\end{array}$ & Sig. \\
& $\mathrm{B}$ & Std. Error & $\begin{array}{l}\text { Coefficients } \\
\text { Beta }\end{array}$ & \\
& 19.955 & 3.107 & & 6.423 & .000 \\
\hline (Constant) & .442 & .096 & .423 & 4.627 & .000 \\
\hline logistik service quality & .423 &
\end{tabular}

a. Dependent Variable: Kepuasan Konsumen

Sumber : Data diolah 2020

Hasil statistik uji t untuk variabel pada produk CV Cahaya Mulia di Kota Bima di peroleh nilai sebesar $t$ hitung sebesar 4.627 dengan nilai tabel sebesar1.985 ( 4.627 $>1.9185$ ) dengan nilai signifikansi sebesar 0.000 lebih kecil dari 0,05 $(0.000<0,05$ ) maka hipotesis yang menyatakan bahwa logistik service quality mempengaruh positif dan signifikan terhadap kepuasan konsumen pada produk CV Cahaya Mulia di Kota Bima dapat diterima.

Dengan demikian dapat dinyatakan bahwa konsumen memiliki sikap positif terhadap produk CV Cahaya Mulia di Kota Bima, sehingga kepuasan konsumen dapat terus meningkat. Penyediaan keragaman produk yang lebih bervariasi dan kualitas pelayanan terutama waktu memproduksi sampai pengantaran terus ditingkatkan agar kepuasan konsumen tetap ada

Diskusi 


\section{Pengaruh logistik service quality terhadap kepuasan konsumen}

Berdasarkan hasil penelitian diatas menyatakan bahwa logistik service quality berpengaruh terhadap kepuasan konsumen. Penelitian ini sejalan dengan hasil penelitian yang dilakukan oleh Hendry \& Ericko (2015) menyatakan bahwa logistic service quality berpengaruh terhadap Kepuasan Konsumen pada Kentucky Fried Chicken di Surabaya dan penelitian Japarianto (2018 yang menyatakan bahwa hasil penelitian menunjukkan logistics service quality berpengaruh signifikan terhadap customer retention melalui customer satisfation.

\section{KESIMPULAN}

Masyarakat kota dan kabupaten bima sudah mengenal dan mengunakan produk berbahan alumunium yaitu lemari kaca,loring dorr dan lain lain yang berbahan alumunium. Hal ini bisa di buktikan dengan penelitian yang peneliti lakukan, di mana logistik service quality berpengaruh terhadap kepuasan konsumen pada produk CV Cahaya Mulia di Kota Bima, dimana nilai sebesar thitung sebesar 4.627 dengan nilai tabel sebesar1.985 ( $4.627>1.9185$ ) dengan nilai signifikansi sebesar 0.000 lebih kecil dari 0,05 ( $0.000<0,05$ ). CV Cahaya Mulia di Kota Bima sekarang sudah memproduksi produk yang lebih bervariatif sesuai dengan permintaan konsumen. Strategi pemasaraan yang di lakukan oleh produsen seharusnya dapat meningkatkan penjualan prodak yang berbahan alumunium dengan intens melakukan promosi baik media sosial maupun dari masyarakat yang ada di Kota Bima maupun di Kabupaten Bima

\section{E. DAFTAR PUSTAKA}

Ghozali, Imam. (2006). Aplikasi Analisis Multivariate dengan Program SPSS (Edisi Ke 4). Semarang:Badan Penerbit Universitas Diponegoro.

Handi Irawan. (2004). Prinsip-prinsip Kepuasan Pelanggan. Jakarta. PT. Elex Media Komputindo

Hartono, Jogiyanto. (2010). Metodologi Penelitian Bisnis: Salah Kaprah dan Pengalaman-Pengalaman. Edisi Pertama. BPFE. Yogyakarta

Hendri Raymond \& Ericko Yohji, 2015. Pengaruh Logistic Service Quality terhadap kepuasan dan loyalitas konsumen kentucky fried chiken di surabaya. Jurna Hospotal dan Manajemen Jasa Vol 3 No 2.

Ho,Yin J.S. Teik, Lai, D, O. Felicia F. K.\&. Tat Yang.T. (2012). Logistik Service Quality Among cuarier in Malasya. International Conference On Economics, Businnes Innovation. IPEDR vol.38. IACSIT Press, Singapure.

Japarianto Edwin, 2018. Pengaruh Logistics Service Quality Terhadap Customer Retention Dengan Customer Satisfaction Sebagai Variabel Intervening Pada Industri Ekspedisi Laut Di Surabaya. Jurnal Manajemen Pemasaran, Vol. 12, No. 1 Hal 25-32

Kotler, Philip and Gary Amstrong. (2016). Prinsip-prinsip Pemasaran. Edii13. Jilid 1. Jakarta:Erlangga

Kotler, K.(2009). Manajemen Pemasaran 1.Edisi ketiga belas. Jakarta: Erlangga 
Malhotra, N. (2015). Marketing Research: An Applied Orientation ath edition. New Jersey: Pearson Education Inc.

Mentzer, J , T. (2016) 21 st Century Logistics: Making Supply Chain Integration a Reality Aok Brook. IL: Council Of Logistics Management

Otsetova Anna. (2017). "Relationship Between Logistics Service Quality, Customer Satisfaction And Loyalty In Courier Services Industry". Management And Education Vol. XIII (1).

Politis Yannis, Giovanis Apostolos, Binioris Spyrido. (2014)."Logistics service quality and its effects on customer satisfaction in the manufacturing companies' supply chains", Journal of Modelling in Management, Vol. 9 Iss 2 pp. $215-237$

Rafiq Muhammed \& Jaafar S Harlina. (2007). “Measuring Customers' Perceptions Of Logistics Service Quality Of 3pl Service Providers.", Journal of Business Logistics, Vol. 28, No. 2

Saura Gil Irene, Francés Servera David, Contrí Berenguer Gloria, Blasco Fuentes Maria, (2008). "Logistics service quality: a new way to loyalty". Industrial Management \& Data Systems, Vol. 108 Issue: 5, 650-668.

Thai, V. V. (2013). “Logistics Service Quality: Conceptual Model and Empirical Evidence". International Journal of Logistics Research and Applications: A Leading Journal of Supply Chain Management, 114-131.

Winarno Heru \& Absor Tb. (2018). Analisis Kualitas Pelayanan Dengan Metode Service Quality (Servqual) Dan Importance Performance Analysis (Ipa) Pada Pt. Media Purna Engineering. Jurnal Manajemen Industri dan Logistik Vol. 1 No. 2 hal 146-159 